\title{
Влияние повышенной битуминозности на петрофизические свойства и ее связь с определенными литологическими типами (по данным исследования доманиковых отложений)
}

\section{Т.В. Павленко}

Камский научно-исследовательский институт комплексных исследований глубоких и сверхглубоких скважин, 614016, Пермь, ул. Краснофлотская, 15 E-mail: mois_tan@mail.ru (Статья поступила в редакиию 20 апреля 2015 г.)

\begin{abstract}
Доманиковые отложения уже давно привлекают внимание геологов-нефтяников как потенциальный источник нефти. Успехи в добыче сланцевого газа и нефти в Америке породили интерес к толщам, обогащенным органическим веществом, как источникам сланцевой нефти. Поэтому знание литологии, битуминозности, типов коллекторов, структуры порового пространства доманиковых отложений и их петрофизических свойств актуально. В статье представлены результаты изучения отложений доманикового типа в разрезе Ново-Сырьянской скважины, дана их литологическая характеристика, выявлены связи повышенного содержания битумоидов с определенными литотипами пород.

Ключевые слова: доманиковые отложения, литотип, известняк, доломит, мергель.

DOI: $10.17072 /$ psu.geol.28.75
\end{abstract}

\section{Введение}

Постоянная забота о приросте или восполнении запасов нефти требует выявления новых, нетрадиционных объектов поисков, разведки и добычи углеводородного сырья. В этом плане особое внимание привлекают доманикиты, которые пока относятся к «недооцененным», «нетрадиционным», с трудноизвлекаемыми запасами.

Считается, что к породам доманикового типа относятся осадочные отложения с концентрацией органического вещества (OB) более $2 \%$. Среди доманиковых отложений развиты две разновидности: собственно, доманикиты и доманикоиды. Подобное разделение связано с различными концентрациями органического углерода
(Сорг) в породе: при Сорг $<5 \%$ отложения относятся к доманикоидам, от 5 до 20 $\%$ - доманикитам, при повышенных содержаниях Сорг (>20\%) породы классифицируются как горючие сланцы $[1,5]$.

Доманикиты образуются обычно в морских бассейнах в условиях длительного некомпенсированного пригибания с низкими скоростями седиментации - это типично депрессионные фации. Основными породообразующими компонентами являются карбонаты, кремнезем и глинистая составляющая. Особенность этих толщ - повышенное содержание кремнезема и ОВ $[6,8]$.

Доманиковые отложения не только являются нефтегазоматеринскими породами Волго-Уральской нефтегазоносной провинции, но и рассматриваются в настоя- 
щее время как перспективные для поисков промышленных скоплений нефти и газа по аналогии с доманикитами ТиманоПечорской нефтегазоносной провинции и баженовитами Западной Сибири. Поэтому знание литологии, битуминозности, типов коллекторов, структуры порового пространства доманиковых отложений и их петрофизических свойств очень важно [9, 11].

В данной работе представлены результаты изучения отложений доманикового горизонта, вскрытых Ново-Сырьянской поисково-оценочной скважиной 1 в интервале глубин 1095,00-1126,00 м.

\section{Общие сведения о геологическом стро- ении и нефтегазоносности района}

Ново-Сырьянская скважина 1 расположена в Белохолунинском районе Кировской области в 70 км к северо-востоку от г. Кирова. В тектоническом отношении данная территория приурочена к Центрально-Сырьянскому поднятию ШиховоСырьянского вала Казанско-Кажимского прогиба Волго-Камской антеклизы. Согласно нефтегазогеологическому районированию она относится к ТокмовскоКажимской НГО Волго-Уральской НГП. Осадочный разрез, вскрытый скважиной, представлен терригенно-карбонатными отложениями от верхнедевонского до четвертичного возраста. Фактическая глубина скважины 1870 м.

В процессе бурения были испытаны отложения доманикового горизонта и среднетиманского подгоризонта верхнего девона. В результате опробования из доманиковых пород получен приток минерализованной воды дебитом $18,5 \mathrm{~m}^{3} /$ сут, а из верхней части среднетиманских отложений - приток безводной нефти удель-

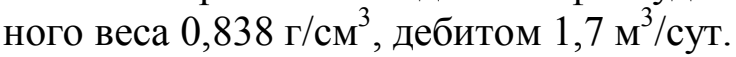

\section{Комплексная характеристика домани- ковых отложений}

Изученные отложения представлены битуминозными мергелями, доломитовы- ми и известково-доломитовыми, переслаивающимися с битуминозными известняками и битуминозными доломитами в разной степени глинистыми, окремненными, пиритизированными.

Такое литологическое разнообразие приводит к значительной вариации плотностных свойств. Объемная плотность доманиковых отложений изменяется от

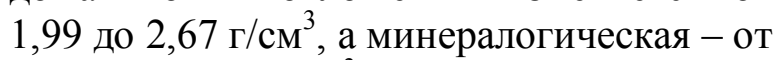

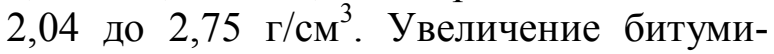
нозности отложений значительно понижает плотностные параметры.

Исследованные доманиковые отложения также характеризуются значительной вариацией фильтрационно-емкостных параметров. По величине открытой пористости более $80 \%$ образцов являются плотными, низкопористыми, лишь незначительная часть образцов пониженнопористые $[3,4]$. По величине абсолютной газопроницаемости породы доманикового возраста практически не проницаемые (до 60 \% выборки), либо полупроницаемые. Значительная изменчивость фильтрационных характеристик, при относительно равных значениях пористости, связана с развитием трещиноватости. В связи с чем отмечается отсутствие связи между пористостью и проницаемостью пород [7].

Изучение акустических свойств пород доманикового возраста также позволило выявить связь вариации интервальных времен пробега продольных и поперечных волн с битуминозностью отложений. Увеличение содержания битумоидов приводит к замедлению скорости прохождения акустических волн.

Далее вся совокупность исследованных образцов по данным микро- и макроописания пород, лабораторного изучения вещественного состава была разделена на три литологические группы:

\footnotetext{
- глинисто-кремнисто-карбонатные породы;

- слабоглинистые доломитизированные известняки и доломиты;

- глинистые доломиты и известняки, мергели.
} 
Реальность и обоснованность разделения пород на данные группы были подтверждены результатами кластерного и дискриминантного анализов, проведенных с помощью программы «Статистика» $[2$, 12].

Кластерный анализ объединяет различные процедуры, используемые для проведения классификации. В результате применения этих процедур исходная совокупность объектов разделяется на кластеры (классы) схожих между собой объектов. Кластерный метод - это многомерная статистическая процедура, собираю- щая данные, которые содержат информацию о выборке объектов, и затем упорядочивающая объекты в сравнительно однородные группы.

При разбиении данных на 2 кластера отмечается недостаточность выделенных комплексов (групп). При разделении массива данных на 4-5 кластеров выделенные группы близки по своим показателям друг к другу.

Оптимальным вариантом для объединения пород в комплексы является выделение 3 кластеров (рис. 1).

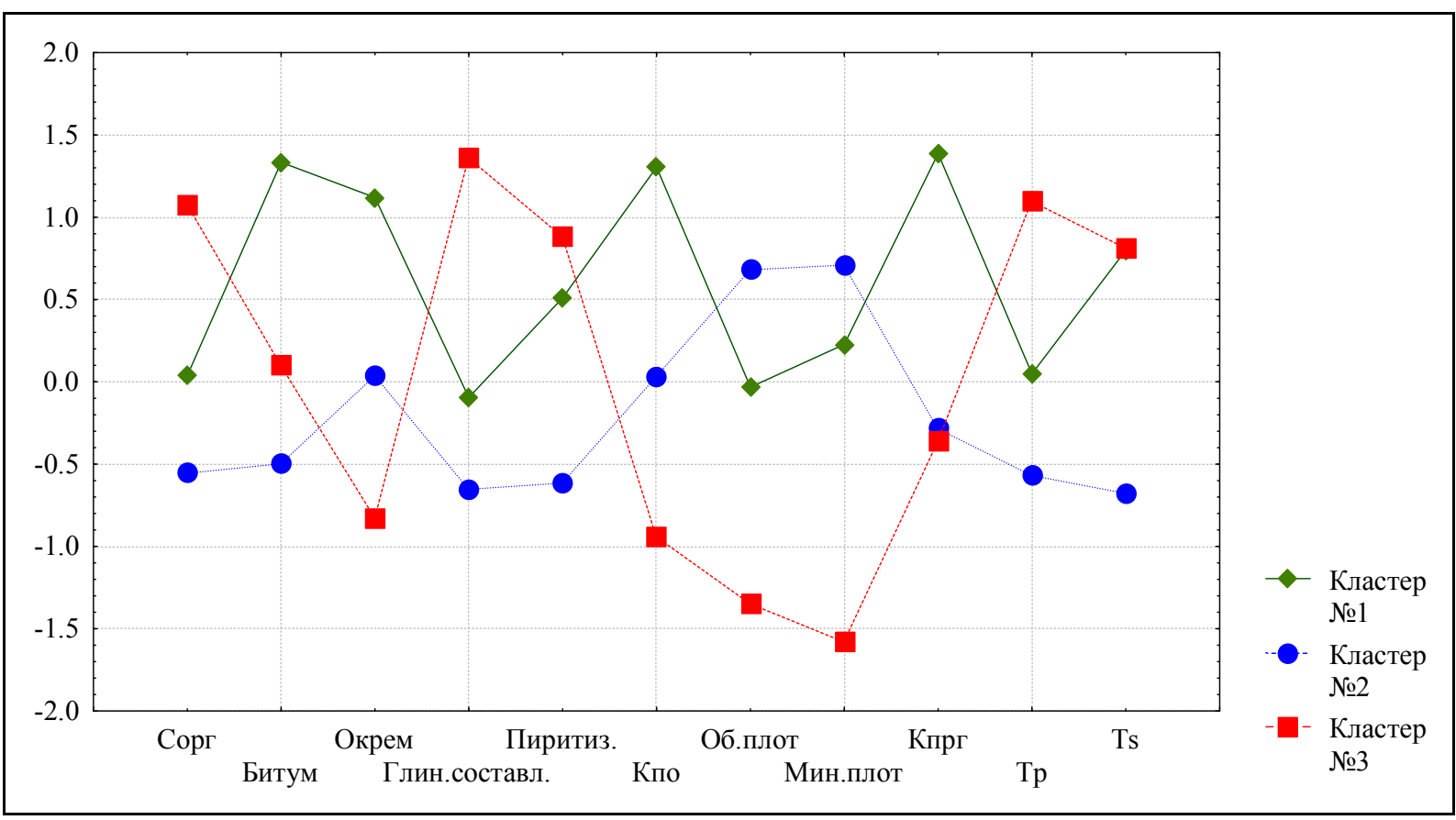

\begin{tabular}{|l|l|}
\hline Кластер 1 & глинисто-кремнисто-карбонатные породы \\
\hline Кластер 2 & чистые и слабоглинистые известняки и доломиты \\
\hline Кластер 3 & глинистые известняки и доломиты \\
\hline
\end{tabular}

Рис. 1. График средних для каждого кластера (при разбиении на 3 класса) пород доманиковых отложений Ново-Сырьянской скважины 1

При разделении массива данных на 3 класса выделяются 3 комплекса пород, каждый из которых характеризуется определенными физическими свойствами.

Начнем с 3-го комплекса. Исходя из представленного графика можно сказать, что породы данного комплекса резко отличаются от остальных пониженными значениями окремнения, пористости, объ- емной и минералогической плотностей. И наоборот, характеризуются повышенными значениями органического углерода, глинистости и интервальных времен пробега акустических волн. К данному комплексу относятся глинистые известняки и доломиты.

2-й комплекс характеризуется низкими значениями органического углерода, со- 
держания битумов, глинистой составляющей, интервальных времен пробега акустических волн. В этот комплекс входят чистые и слабоглинистые известняки и доломиты.

1-й комплекс отличается высокими значениями окремнения, содержания битумов, пористости и проницаемости. К данному комплексу относятся глинистокремнисто-карбонатные породы.

Следующим этапом многомерного статистического анализа был дискриминантный анализ, который выполняет две основные задачи: интерпретации и классификации.

Цель интерпретации - найти ответы на следующие вопросы: возможно ли, используя данный набор характеристик, отличить один класс от другого; насколько хорошо эти характеристики позволяют провести различие и какие из них наиболее информативны.

Весь массив информации включал данные о содержании органического уг- лерода, хлороформенного битумоида, окремнения, пиритизации, глинистости, значения открытой пористости, объемной и минералогической плотностей, газопроницаемости и интервальных времен пробега акустических волн. Определяющими параметрами система выбрала 3: минералогическая плотность, окремнение и содержание хлороформенного битумоида (рис. 2).

В результате пошагового анализа методом включения были найдены следующие канонические функции:

$$
\begin{aligned}
f_{\kappa} 1= & 32,24 \cdot \delta_{\text {Кмп }}+0,94 \cdot C_{\mathrm{SiO}_{2}} \\
& +0,2 \cdot \text { Бхл }-83,7, \\
f_{\kappa} 2= & -13,59 \cdot \delta_{\text {кмп }}+2,88 \cdot C_{\mathrm{SiO}_{2}} \\
& -0,95 \cdot \text { Бхл }+34,1,
\end{aligned}
$$

где $\delta_{\text {кмп }}-$ кажущаяся минералогическая плотность, $\mathrm{C}_{\mathrm{SiO} 2}$ - окремнение, Бхл - хлороформенный битумоид.

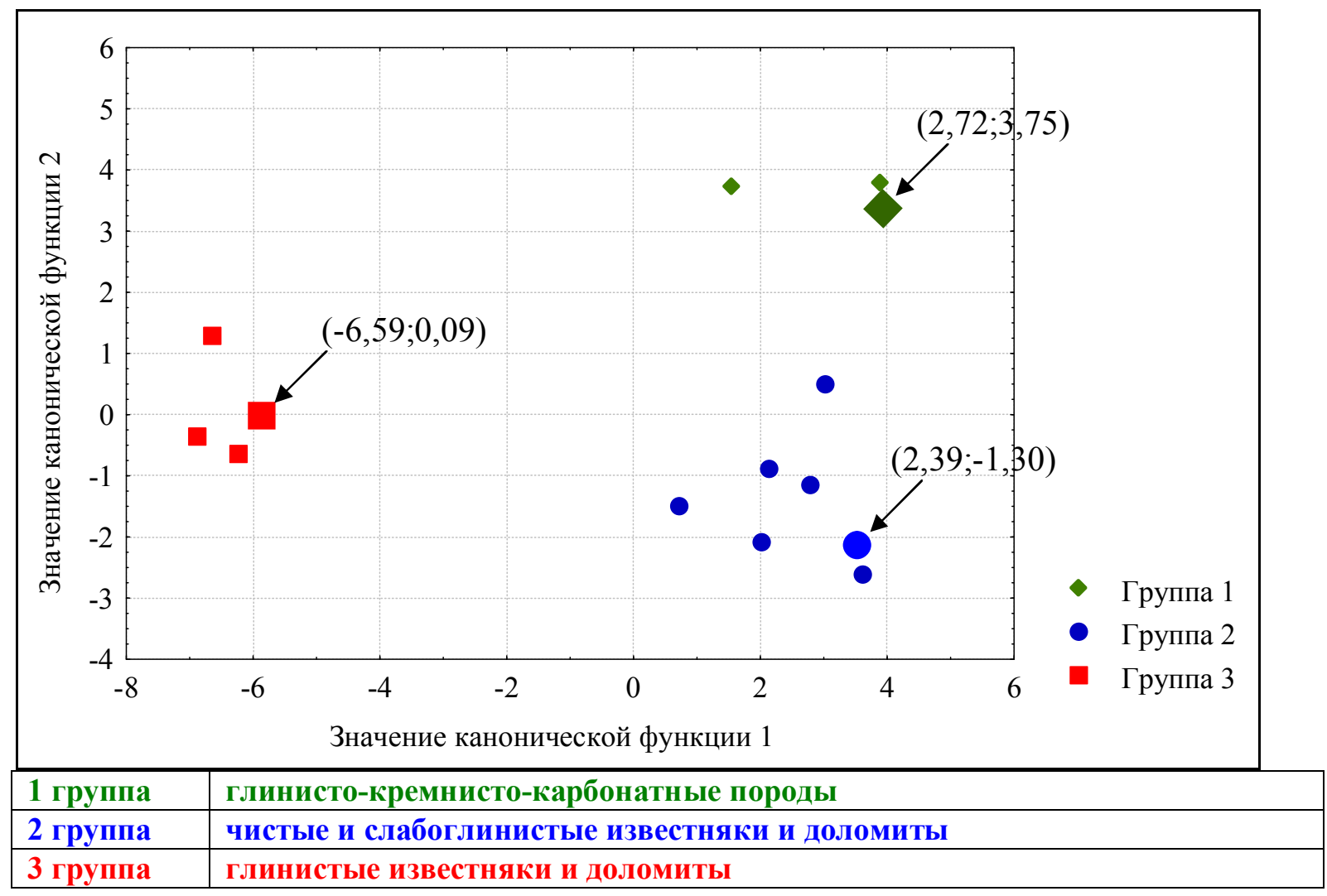

Рис. 2. Разделение 3 групп пород по результатам дискриминантного анализа доманиковых отложений Ново-Сырьянской скважины 1 
Величина собственного значения связана с дискриминирующими возможностями этой функции: чем больше собственное значение, тем лучше различие [10].

Собственное число для первой функции $\lambda=22,4$ при каноническом коэффициенте корреляции $\mathrm{r}^{*}=0,98$. Собственное число для второй функции $\lambda=4,77$ при каноническом коэффициенте корреляции $\mathrm{r}^{*}=0,91$.

Соответственно первая функция лучше разделяет массив данных, чем вторая. Первая функция хорошо отделяет третью группу от первой и второй, а вторая каноническая функция отделяет первую группу от второй и третьей.

Значение лямбды Уилкса равно 0,0074 (приближается к 0), что свидетельствует о хорошем разделении.

Правильность разделения на группы также была проверена с помощью квадратов расстояний Махаланобиса от точек (случаев) до центров групп. Случай относится к группе, до которой расстояние Махаланобиса минимально. Если случай (образец) неправильно классифицирован, то напротив данного значения ставится *. В нашем случае отмечается верное разделение на группы.

Классификационная задача дискриминантного анализа состоит в том, чтобы определить вероятность отнесения образца к одной из групп пород.

Функции классификации, построенные пошаговым методом включения, имеют вид

$$
\begin{aligned}
Z_{1}= & 3222,93 \cdot \delta_{K M \Pi}-4,09 \cdot C_{\mathrm{SiO}_{2}} \\
& +52,04 \cdot \text { Бхл }-4220,32, \\
Z_{2} & =3280,83 \cdot \delta_{K M \Pi}-18,91 \cdot C_{\mathrm{SiO}_{2}} \\
& +56,76 \cdot \text { Бxл }-4356,53, \\
Z_{3} & =2971,71 \cdot \delta_{\text {КMП }}-23,39 \cdot C_{\mathrm{SiO}_{2}} \\
& +53,64 \cdot \text { Бхл }-3576,63,
\end{aligned}
$$

где $Z_{1}$ - группа глинисто-кремнистокарбонатных пород, $Z_{2}$ - группа чистых, слабоглинистых известняков и доломитов,
$Z_{3}$ - группа глинистых известняков и доломитов.

Таким образом, первую группу пород слагают окремненные глинистые доломиты и известняки, а также мергели. Карбонаты мелко-, тонкозернистые, органогенно-детритовые, обломочные, иногда брекчированные, массивные, реже неяснослоистые, слоистость подчеркивается глинисто-битуминозными прожилками. Породы неравномерно тонкопористые, поры межзерновые неправильнотреугольной, вытянутой формы, размером до 0,1 мм, с частыми тонкими полыми разноориентированными трещинами раскрытостью до 0,04 мм, с редкими раздувами до 0,3 мм. Содержание Сорг в глинисто-кремнисто-карбонатных породах группы изменяется от 0,5 до $6,0 \%$ при среднем значении 3,6 \%. Почти все породы выборки относятся к доманикоидам. Битуминозность отложений повышенная и высокая - содержание Бхл от 0,04 до 5,0 \%. Породы группы низко- и пониженнопористые с пористостью, варьирующей в диапазоне от 0,3 до $8,9 \%$. По величине газопроницаемости отложения классифицируются как полупроницаемые, практически непроницаемые и породы-экраны. Газопроницаемость пород изменяется от 0,0001 до $9,8 \cdot 10^{-15} \mathrm{~m}^{2}$.

Вторую группу пород слагают доломитизированные известняки и доломиты, слабоглинистые, неравномерно глинистые, мелко-, тонкозернистые, органогенно-детритовые, тонкослоистые, с частыми остатками тентакулитов, раковин брахиопод и остракод, плотные, участками тонкопористые, с редкими внутрифрагментарными порами неправильной формы размером до 0,01 мм и тонкими полыми секущими быстро затухающими трещинами, ориентированными преимущественно по слоистости, раскрытостью до 0,01 мм. Органическое вещество распределено в породе неравномерно, концентрируется в виде тонких слойков, линзовидных примазок в межзерновом и межформенном пространстве. Пиритизация слабая, рассеянная, единичные изомет- 
ричные включения распределены неравномерно. Содержание Сорг в породах данной группы изменяется от 0,5 до 7,7 \% при среднем значении 3,8 \%. Породы выборки (до $70 \%$ ) относятся к доманикоидам. Содержание Бхл от низких до высоких значений (0,01-2,5 \% при среднем значении 0,58 \%). Породы группы понижено-пористые с пористостью, варьи- рующей в диапазоне от 2,5 до 9,1 \%. По величине газопроницаемости отложения классифицируются как полупроницаемые, практически непроницаемые и породыэкраны. Дисперсия газопроницаемости пород от 0,0001 до $4,1 * 10^{-15} \mathrm{M}^{2}$ при среднегеометрическом значении, равном $0,006 \cdot 10^{-15} \mathrm{M}^{2}$.

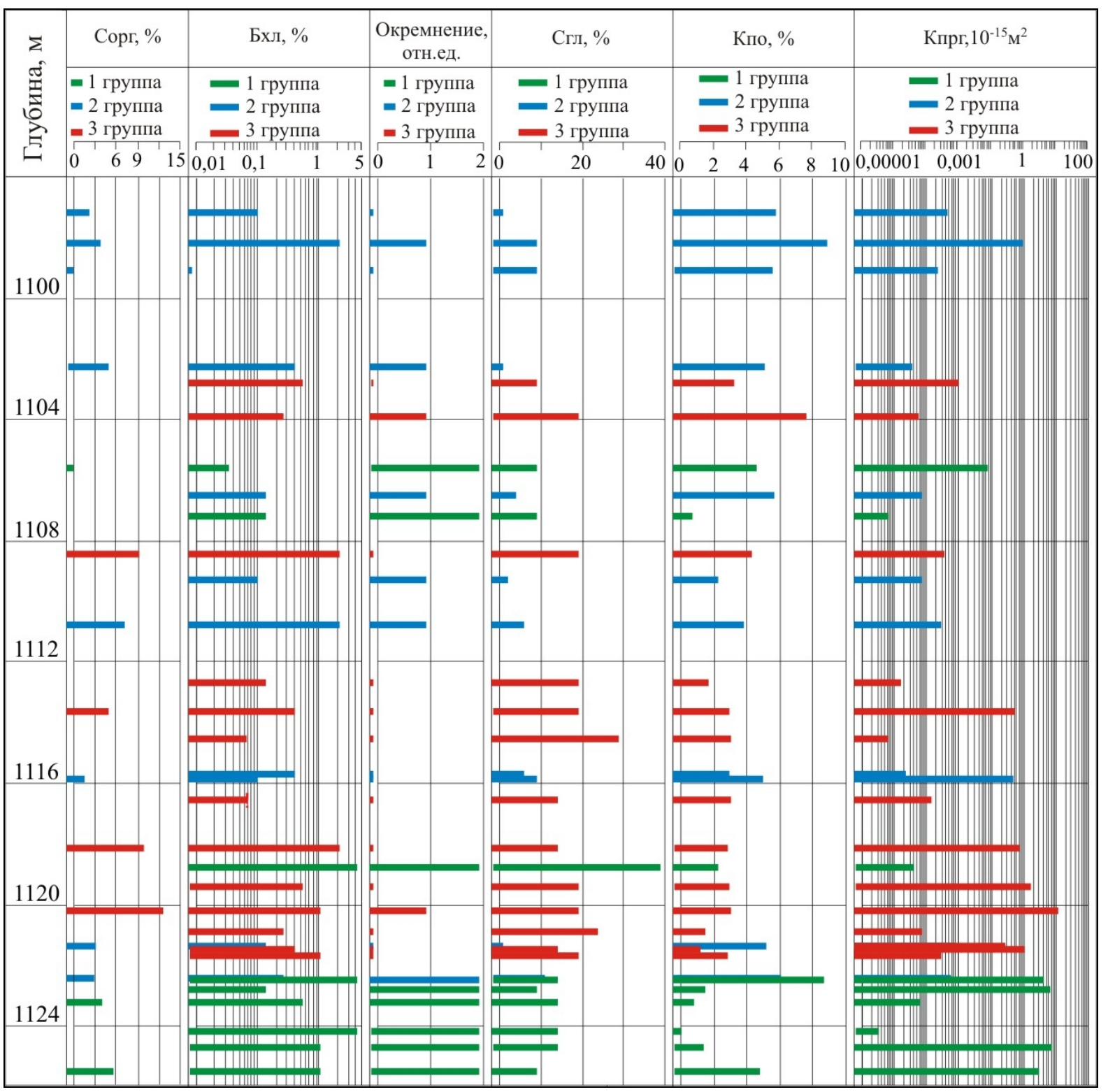

\begin{tabular}{|l|l|}
\hline 1 группа & глинисто-кремнисто-карбонатные породы \\
\hline 2 группа & чистые и слабоглинистые известняки и доломиты \\
\hline 3 группа & глинистые известняки и доломиты \\
\hline
\end{tabular}

Рис. 3. Сводный разрез доманиковых отложений Ново-Сырьянской скважины 1 
Глинистые известняки, доломитовые и известково-доломитовые мергели, слагающие третью группу пород, тонкозернистые, органогенно-детритовые, тонкослоистые, с частыми остатками тентакулитов, плотные, редко неравномерно тонкопористые, с частыми ветвящимися полыми трещинами раскрытостью до 0,2 мм. Глинисто-битуминозный материал равномерно пропитывает породу, образует тонкие ветвящиеся прожилки. Пирит неравномерно рассеян в породе, часто в виде крупных стяжений округлой формы размером до 5 мм, иногда встречаются псевдоморфозы по фаунистическим остаткам. Содержание Сорг в глинистокарбонатных породах данной группы изменяется от 5,5 до 13,3 \% при среднем значении 9,7 \%. Породы выборки относятся к доманикитам. Битуминозность отложений повышенная и высокая. Содержание Бхл - от 0,08 до 2,5\%. Породы группы низко- и пониженно-пористые с диапазоном изменения параметра от 1,4 до 7,9\%. По величине газопроницаемости отложения классифицируются как проницаемые, полупроницаемые, практически непроницаемые и породы-экраны. Газопроницаемость пород изменяется от 0,0001 до $17 \cdot 10^{-15} \mathrm{M}^{2}$.

В ходе работы был построен сводный разрез, на котором были отображены содержание Сорг и Бхл, окремнение, глинистость (Сгл), а также коллекторские свойства изучаемой толщи с разбивками на литологические группы (рис. 3).

В результате проведения сравнительного анализа сделаны выводы о том, что повышенное содержание ОВ отмечается в глинисто-карбонатных разностях, мергелях, а также в ряде глинисто-кремнистокарбонатных пород. Наиболее низкие концентрации ОВ характерны для известняков и доломитов, слабоглинистых либо не имеющих в своем составе глинистой составляющей.

Содержание битумоидов в породах значительно варьирует. Повышенное содержание Бхл отмечается в породах 3-й группы, представленных глинистыми из- вестняками и доломитами, мергелями, а также в породах 1-й группы, представленных глинисто-кремнисто-карбонатными породами. Отмечается тенденция: повышенное значение Бхл соответствует повышенной глинистости отложений.

Анализ фильтрационно-емкостных свойств доманиковых отложений показал, что наиболее низкими коллекторскими свойствами обладают породы типичной доманиковой формации - битуминозные глинисто-карбонатные и глинистокремнисто-карбонатные разности. Улучшению фильтрационно-емкостных характеристик способствует развитие вторичной доломитизации, выщелачивания и трещиноватости пород.

\section{Заключение}

В данной работе представлены общие сведения о геологическом строении и нефтегазоносности района НовоСырьянской поисково-оценочной скважины 1, выявлены связи повышенного содержания битумов и петрофизических параметров, выделены различные по литотипу группы пород и дана их комплексная характеристика по данным литологических, геохимических и петрофизических исследований, в конечном итоге построен сводный разрез и сделаны выводы о приуроченности повышенного содержания битумов к определенным литологическим типам пород.

В ходе выполнения работы были получены следующие геологические результаты:

1. Содержание битумоидов в породах доманиковых отложений значительно варьирует. Увеличение содержания Бхл приводит к снижению минералогической плотности, и наоборот, с ростом этого параметра разрез становится все более низкоскоростным (значения интервальных времен пробега акустических волн увеличиваются).

2. В ходе сравнительного анализа различных литологических групп пород отмечено, что повышенное содержание Бхл 
отмечается в группе, представленной глинистыми известняками и доломитами, мергелями, а также в группе, представленной глинисто-кремнисто-карбонатными породами.

3. Отмечается тенденция: повышенное значение битумоидов соответствует повышенным значениям глинистости.

4. Анализ фильтрационно-емкостных свойств доманиковых отложений показал, что наиболее низкими коллекторскими свойствами обладают породы типичной доманиковой формации - битуминозные глинисто-карбонатные и глинистокремнисто-карбонатные разности.

\section{Библиографический список}

1. Баженова О.К., Бурлин Ю.К. и др. Геология и геохимия нефти и газа. М.: Изд-во МГУ, $2000.384 \mathrm{c}$.

2. Боровиков В.П. Популярное введение в программу STATISTICA. М.: КомпьютерПресс, 1998. 267 c.

3. Добрынин В.М., Вендельштейн Б.Ю., Кожевников Д.А. Петрофизика. М.: Недра, $1991.368 \mathrm{c}$.
4. Дортман Н.Б. Петрофизик: справочник в трех книгах. Книга первая. Горные породы и полезные ископаемые. М.: Недра, 1992. $391 \mathrm{c}$.

5. Ермолкин В.И., Керимов В.Ю. Геология и геохимия нефти и газа. М.: Недра, 2012. $460 \mathrm{c}$.

6. Кирюхина Т.А., Фадеева Н.П. и др. Доманиковые отложения Тимано-Печорского и Волго-Уральского бассейнов // Геология нефти и газ. 2013. № 3. С. 76-87.

7. Кобранова В. Н. Петрофизика. М.: Недра, 1986. $392 \mathrm{c}$.

8. Леворсен А. Геология нефти и газа / пер. с англ. И.Т. Дубовского, М.Ш. Моделевского и Г.Ф. Ульмишека. М.: Мир, 1970. 640 с.

9. Справочник по геологии нефти и газа / под ред. Н.А. Еременко. М.: Недра, 1984. 480 c.

10. Факторный, дискриминантный и кластерный анализ / пер. с англ. Дж.-О.Ким и др.; под ред. И.С. Енюкова. М.: Финансы и статистика, 1989. 215 с.

11. Хант Дж. Геохимия и геология нефти и газа / пер. с англ. А.И. Конюхова, Г.В. Семерниковой и В.В. Чернышева. М.: Мир, 1982. 704 с.

12. Шарапов И.П. Применение математической статистики в геологии. М.: Недра, 1971. $248 \mathrm{c}$.

\section{Influence of Increased Bituminosity on the Petro- physical Properties and its Relationship with Specific Lithological Types According to Results of Study of Domanik Formations}

\section{T.V. Pavlenko}

Kama Research Institute on Complex Deep and Superdeep Borehole Investigations, 15 Krasnoflotskaya Str., Perm 614016, Russia

E-mail: mois_tan@mail.ru

Domanik formations have attracted the attention of petroleum geologists for long time as a potential source of oil. Advances in the production of shale gas and oil in the United States have generated attention to enriched in organic matter rock mass as sources of shale oil. To get correct evaluation of strata potential, it is important to know the lithology, bituminosity, reservoir type, the structure of porosity of Domanik sediments, and their petrophysical properties. The article presents the results of study of Domanik formations in the cross-section of the New Syryansk borehole, their lithological characteristics, identified the relationship between the content of bitumens and specific lithotypes.

Key words: Domanik formations, lithotype, limestone, dolomite, chalky clay. 


\section{References}

1. Bazhenova D.C., Burlin J.K. et al. 2000. Geologiya i geokhimiya nefti i gaza [Geology and geochemistry of Oil and Gas]. MSU, Moskva, p. 384. (in Russian)

2. Borovikov V.P. 1998. Populyarnoe vvedenie $\mathrm{v}$ programmu STATISTIKA [Popular introduction to the program STATISTICA]. ComputerPress, Moskva, p. 267. (in Russian)

3. Dobrynin V.M., Vendelshteyn B.J., Kozhevnikov D.A. 1991. Petrofizika [Petrophysics]. Nedra, Moskva, p. 368. (in Russian)

4. Dortman N.B. Petrophizika [Petrophysics]. Reference Book. In three books. The first book. Rocks and minerals. M.: Nedra, 1992. $391 \mathrm{p}$.

5. Ermolkin V.I., Kerimov V.Y. 2012. Geologiya i geokhimiya nefti i gaza [Geology and geochemistry of oil and gas]. Nedra, Moskva, p. 460. (in Russian)

6. Kiryukhina T.A., Fadeev N.P. et al. 2013. Domanikovye otlozheniya Timano-Pechorskogo i Volgo-Uralskogo basseynov [Domanik formations of Timan-Pechora and VolgaUrals Basins]. Oil and Gas Geology, 3:76-87. (in Russian)

7. Kobranova V.N. 1986. Petrofizika [Petrophysics]. Nedra, Moskva, p. 392. (in Russian)

8. Levorsen A.I. 1956. Geology of petroleum. W.H. Freeman, San Francisco, p. 703.

9. Spravochnik po geologii nefti i gaza [Handbook of Petroleum Geology]. N.A. Eremenko $(E d$.$) . Nedra, Moskva, 1984, p. 480. (in Rus-$ sian)

10. Kim J.-O., Myuller Ch.U., Klekka U.R. et al. 1989. Faktornyy, diskriminantnyy i klasterhyy analiz [Factor, discriminant and cluster analysis]. Finansy i Statistika, p. 215. (in Russian)

11. Hunt J.M. 1995. Petroleum Geochemistry and Geology. W.H. Freeman, New York, p. 743.

12. Sharapov I.P. 1971. Primenenie matematicheskoy statistiki v geologii [Application of mathematical statistics in geology]. Nedra, Moskva, p. 248. (in Russian) 